\title{
Increased platelet-lymphocyte ratio closely relates to inferior clinical features and worse long-term survival in both resected and metastatic colorectal cancer: an updated systematic review and meta-analysis of 24 studies
}

\author{
Nan Chen ${ }^{1, *}$, Wanling Li ${ }^{1, *}$, Kexin Huang ${ }^{1}$, Wenhao Yang ${ }^{1}$, Lin Huang ${ }^{1}$, Tianxin \\ Cong ${ }^{1}$, Qingfang $\mathrm{Li}^{1}$ and Meng Qiu ${ }^{1,2}$ \\ ${ }^{1}$ West China School of Medicine/West China Hospital, Sichuan University, Chengdu, China \\ 2 Department of Medical Oncology, Cancer Center, the State Key Laboratory of Biotherapy, West China Hospital, Sichuan \\ University, Chengdu, Sichuan, China \\ * These authors have contributed equally to this work \\ Correspondence to: Meng Qiv, email: qiumeng33@hotmail.com
}

Keywords: colorectal cancer, platelet-lymphocyte ratio, prognosis, clinical features, meta-analysis

Received: November 14, $2016 \quad$ Accepted: January 24, 2017

Published: March 08, 2017

Copyright: Chen et al. This is an open-access article distributed under the terms of the Creative Commons Attribution License (CC-BY), which permits unrestricted use, distribution, and reproduction in any medium, provided the original author and source are credited.

\section{ABSTRACT}

Colorectal cancer (CRC) is one of the most common cancers worldwide. However, the prognostic and clinical value of platelet-lymphocyte ratio (PLR) in colorectal cancer was still unclear, which attracted more and more researchers' considerable attention. We performed a systematic review and meta-analysis to investigate the relationship between PLR and survival as well as clinical features of CRC update to September 2016. The hazard ratio (HR) or odds ratio (OR) with $95 \%$ confidence interval (CI) were calculated to access the association. We included 24 eligible studies with a total of 13719 patients. Elevated PLR predicted shorter overall survival (OS) $(H R=1.47 ; 95 \% C I, 1.28-1.68 ; p<0.001)$, poorer disease-free survival (DFS) (HR=1.51; 95\% CI, 1.2-1.91; $p=0.001)$, and worse recurrence-free survival (RFS) (HR=1.39; 95\% CI, 1.03-1.86; $p=0.03)$, but had nothing to do with Cancer-specific survival (CSS) (HR=1.14; 95\% CI, 0.92-1.42; $p=0.223$ ). After trim and fill method, the connection between PLR and DFS disappeared (HR=1.143; 95\%CI, 0.903-1.447; $p=0.267$ ). By subgroup analyze, we found that increased PLR predicated a worse OS and DFS in patients who underwent surgery, and this prognostic role also shown both in metastatic and nonmetastatic patients. In addition, elevated PLR was associated with poorly differentiated tumor $(O R=1.51 ; 95 \% C I, 1.26-1.81 ; p<0.001)$, higher tumor stage $(\mathrm{OR}=1.25 ; 95 \% \mathrm{CI}, 1.05-1.49 ; p=0.012)$, lymphovascular invasion (LVI) $(O R=1.25 ; 95 \% C I, 1.09-1.43 ; p=0.001)$, and the recurrence of $C R C(O R=2.78 ; 95 \%$ $C I, 1.36-5.68 ; p=0.005)$. We indicated that pretreatment PLR was a good prognostic marker for CRC patients. High PLR was related to worse OS, RFS and poor clinical characteristics.

\section{INTRODUCTION}

Colorectal cancer (CRC) caused almost 700,000 deaths worldwidely every year, making it the world's fourth most deadly cancer [1]. It was the third most commonly diagnosed cancer in males and the second in females, with an estimated 1.4 million cases and
693,900 deaths occurring in 2012 [2]. The lifestyle changes in past low-CRC-risk countries resulted in rapid growth of colorectal cancer and the 5-year survival rate was still poor despite the progress of the treatment [36]. Pretreatment predicting indexes are in dire need to forecast potential of the tumor recurrence and prognosis for that the majority of the available prognostic markers are assessed postoperatively. The clinical and pathological 
Table 1: Study characteristics

\begin{tabular}{|c|c|c|c|c|c|c|c|c|c|c|c|c|}
\hline Author & Year & Country & Ethnicity & Location & $\mathrm{Na}$ & $\begin{array}{l}\text { Sex(male/ } \\
\text { female) }\end{array}$ & Stage & Metastasis & Treatmentb & $\begin{array}{l}\text { Survival } \\
\text { analysis }\end{array}$ & Analysis & $\begin{array}{l}\text { NOS } \\
\text { score }\end{array}$ \\
\hline Azab & 2014 & USA & Mixed & Colorectal cancer & 580 & $273 / 307$ & I/II/III/IV & $\mathrm{Y}$ & Surgery & OS/DFS & $\mathrm{M} / \mathrm{M}$ & 8 \\
\hline Baranyai & 2014 & Hungary & Caucasian & Colorectal cancer & 336 & $180 / 156$ & I/II/III/IV & $\mathrm{N}$ & Surgery & OS/DFS & $\mathrm{U} / \mathrm{U}$ & 5 \\
\hline Baranyai & 2014 & Hungary & Caucasian & Colorectal cancer & 118 & $80 / 38$ & IV & Y & Surgery & OS & $\mathrm{U}$ & 5 \\
\hline Carruthers & 2012 & UK & Caucasian & Rectal cancer & 115 & $75 / 40$ & I/II/III & Y & Surgery & OS/DFS & $\mathrm{U} / \mathrm{U}$ & 6 \\
\hline Chan & 2016 & Australia & Caucasian & Colorectal cancer & 1623 & $801 / 882$ & $\mathrm{I} / \mathrm{II} / \mathrm{III}$ & $\mathrm{N}$ & Surgery & OS & $\mathrm{U}$ & 8 \\
\hline Choi & 2015 & Canada & Caucasian & Colorectal cancer & 549 & $296 / 253$ & $\mathrm{I} / \mathrm{II} / \mathrm{III}$ & $\mathrm{N}$ & Surgery & OS/RFS & $\mathrm{U} / \mathrm{U}$ & 8 \\
\hline $\mathrm{He}$ & 2013 & China & Asian & Colorectal cancer & 243 & $155 / 88$ & IV & Y & Non surgery & OS & M & 8 \\
\hline Kwon & 2012 & Korea & Asian & Colorectal cancer & 200 & $123 / 77$ & I/II/III/IV & $\mathrm{Y}$ & Surgery & OS & M & 8 \\
\hline $\mathrm{Li}$ & 2016 & China & Asian & Rectal cancer & 140 & $81 / 59$ & $\mathrm{I} / \mathrm{II} / \mathrm{III}$ & $\mathrm{N}$ & Surgery & OS/DFS & $\mathrm{U} / \mathrm{U}$ & 7 \\
\hline $\mathrm{Li}$ & 2016 & China & Asian & Colorectal cancer & 5336 & $3167 / 2169$ & $\mathrm{I} / \mathrm{II} / \mathrm{III}$ & $\mathrm{Y}$ & Surgery & OS/DFS & $\mathrm{M} / \mathrm{M}$ & 6 \\
\hline $\mathrm{Li}$ & 2015 & China & Asian & Colon cancer & 110 & $58 / 52$ & IV & Y & Surgery & OS & M & 7 \\
\hline Mori & 2015 & Japan & Asian & Colorectal cancer & 157 & $87 / 65$ & I/II/III & $\mathrm{N}$ & Surgery & DFS & $\mathrm{U}$ & 6 \\
\hline Neal & 2015 & UK & Caucasian & Colorectal cancer & 302 & $192 / 110$ & IV & Y & Surgery & OS/CSS & $\mathrm{U} / \mathrm{U}$ & 7 \\
\hline Neofytou & 2014 & UK & Caucasian & Colorectal cancer & 140 & $88 / 52$ & IV & Y & Surgery & OS/DFS & $\mathrm{M} / \mathrm{M}$ & 9 \\
\hline Neofytou & 2015 & UK & Caucasian & Colorectal cancer & 140 & $88 / 52$ & IV & Y & Surgery & CSS & $\mathrm{U}$ & 9 \\
\hline Ozawa & 2015 & Japan & Asian & Colorectal cancer & 234 & $142 / 92$ & II & $\mathrm{N}$ & Surgery & DFS/CSS & $\mathrm{M} / \mathrm{M}$ & 7 \\
\hline Passardi & 2016 & Italy & Caucasian & Colorectal cancer & 289 & $174 / 115$ & I/II/III/IV & Y & Non surgery & OS & $\mathrm{M} /$ & 7 \\
\hline Son & 2013 & Korea & Asian & Colon cancer & 624 & $368 / 256$ & $\mathrm{I} / \mathrm{II} / \mathrm{III}$ & $\mathrm{N}$ & Surgery & OS/DFS & $\mathrm{M} / \mathrm{M}$ & 7 \\
\hline Song & 2015 & Korea & Asian & Colorectal cancer & 177 & $83 / 94$ & IV & $\mathrm{N}$ & Non surgery & OS & $\mathrm{U}$ & 5 \\
\hline Sun & 2014 & China & Asian & Colon cancer & 255 & $135 / 120$ & $\mathrm{I} / \mathrm{II} / \mathrm{III}$ & $\mathrm{N}$ & Surgery & OS/DFS & $\mathrm{M} / \mathrm{M}$ & 7 \\
\hline Szkandera & 2014 & Austria & Caucasian & Colon cancer & 372 & $217 / 155$ & II/III & $\mathrm{N}$ & Surgery & OS & M & 7 \\
\hline Toiyama & 2013 & Japan & Asian & Rectal cancer & 84 & $62 / 22$ & $\mathrm{I} / \mathrm{II} / \mathrm{III}$ & $\mathrm{N}$ & Surgery & OS/DFS & $\mathrm{U} / \mathrm{U}$ & 6 \\
\hline Ying & 2014 & China & Asian & Colorectal cancer & 205 & $144 / 61$ & $\mathrm{I} / \mathrm{II} / \mathrm{III}$ & $\mathrm{N}$ & Surgery & OS/CSS/RFS & $\mathrm{M} / \mathrm{M} / \mathrm{M}$ & 7 \\
\hline You & 2016 & China & Asian & Colorectal cancer & 1314 & $785 / 529$ & I/II/III/IV & Y & Surgery & OS & M & 6 \\
\hline Zou & 2016 & China & Asian & Colorectal cancer & 216 & $137 / 79$ & I/II/III/IV & Y & Surgery & OS/DFS & $\mathrm{M} / \mathrm{M}$ & 7 \\
\hline
\end{tabular}

a Number of included patients.

bUnsurgery includes patients undergoing chemotherapy, chemoradiotherapy, or other treatment, but not doing surgery. Surgery including patients getting surgery with or without other treatment.

Abbreviations: NA: not available; OS: overall survival; DFS: disease-free survival; CRM: cancer-ralated mortality; TLR: Time to local recurrence; RFS: recurrence-free survival; CSS: Cancer-specific survival; M: multivariate analysis; U: univariate analysis; NOS: Newcastle-Ottawa Quality Assessment Scale; PLR: platelet-lymphocyte ratio.

TNM stages, the number of resected lymph nodes (nLNs), carcino-embryonic antigen (CEA), the lymphovascular invasion (LVI), the perineural invasion, in addition to some molecular markers (eg. PinX1, RAS, BRAF, MMR and so on) have all been identified as prognostic factors [7-11], however several weaknesses limited their application in routine clinical practice, such as high costs, lack of standardization, low consistency, and poor reproducibility $[7,12,13,14]$. Therefore, finding a proper prognostic factors to assist coloractal cancer patients in guiding appropriate treatment to improve the therapeutic effectiveness is extremely urgent.

Prior studies showed that systemic inflammatory response (SIR) status played a vital role in tumor progression and therapeutic response [15-19]. The levels of platelets and lymphocytes represents the systemic inflammatory response (SIR), and they are easily obtained by widely used peripheral blood test. Platelet-lymphocyte ratio (PLR) as a combination of these two factors has been reported to be associated with poor prognosis in different tumor types, including CRC [20-32], but some other studies drew a different conclusion [33-43]. In brief, independent research results of the relationship between PLR and its impact on survival and clinical features were still inconsistent, partly due to limited published studies previously, various confounding factors and less detailed analysis. Recently, a lot of new studies on this issue were published continuously. Thus the aim of our study was to perform a systemic review and meta-analysis with all eligible current evidence to clarify this relationship and to 
evaluate whether PLR was an independent risk factors for the prognosis of patients with colorectal cancer.

\section{RESULTS}

\section{Literature search and study selection}

A total of 194 relevant publications were initially retrieved. Of these, 29 duplicates were removed, 134 publications were excluded because the studies were animal experiment, literature reviews, comments, letters, or unrelated studies based on the titles and abstracts screening. After reading the full text, 7 publications were excluded due to irrelevant publications, studies with overlapping case series or lack of sufficient data for analysis, Therefore, a total of 24 publications with 13719 patients were included [20-43]. All of these studies contained the required information and evaluated the correlation between PLR and the prognosis of CRC. Figure 1 presents a summary of the study selection process.

\section{Study characteristics}

The main features of the 24 selected studies are shown in Table 1. From the 24 studies, fourteen publications were originated from the Asian (eight from China, three from Korea, three from Japan), nine were performed in Caucasian population (four from the UK, one from Hungary, one from Canada, one from Australia, one from Austria, one from Italy), and one from USA with mixed races. The OS was investigated in 22 studies, the DFS rate was analyzed in 12 studies, the CSS rate was evaluated in 4 studies, and the RFS rate was reported in 2 studies. These eligible studies were published from 2012 to 2016. Thirteen of these directly provided HR in multivariate analysis, and survival data of nine studies were extracted from univariate analysis while survival data of two studies were extracted from survival curves. The extracted data in detail were presented in Supplementary Table S1 and S2, while detailed NOS scores of each included study were presented in Supplementary Table S4.

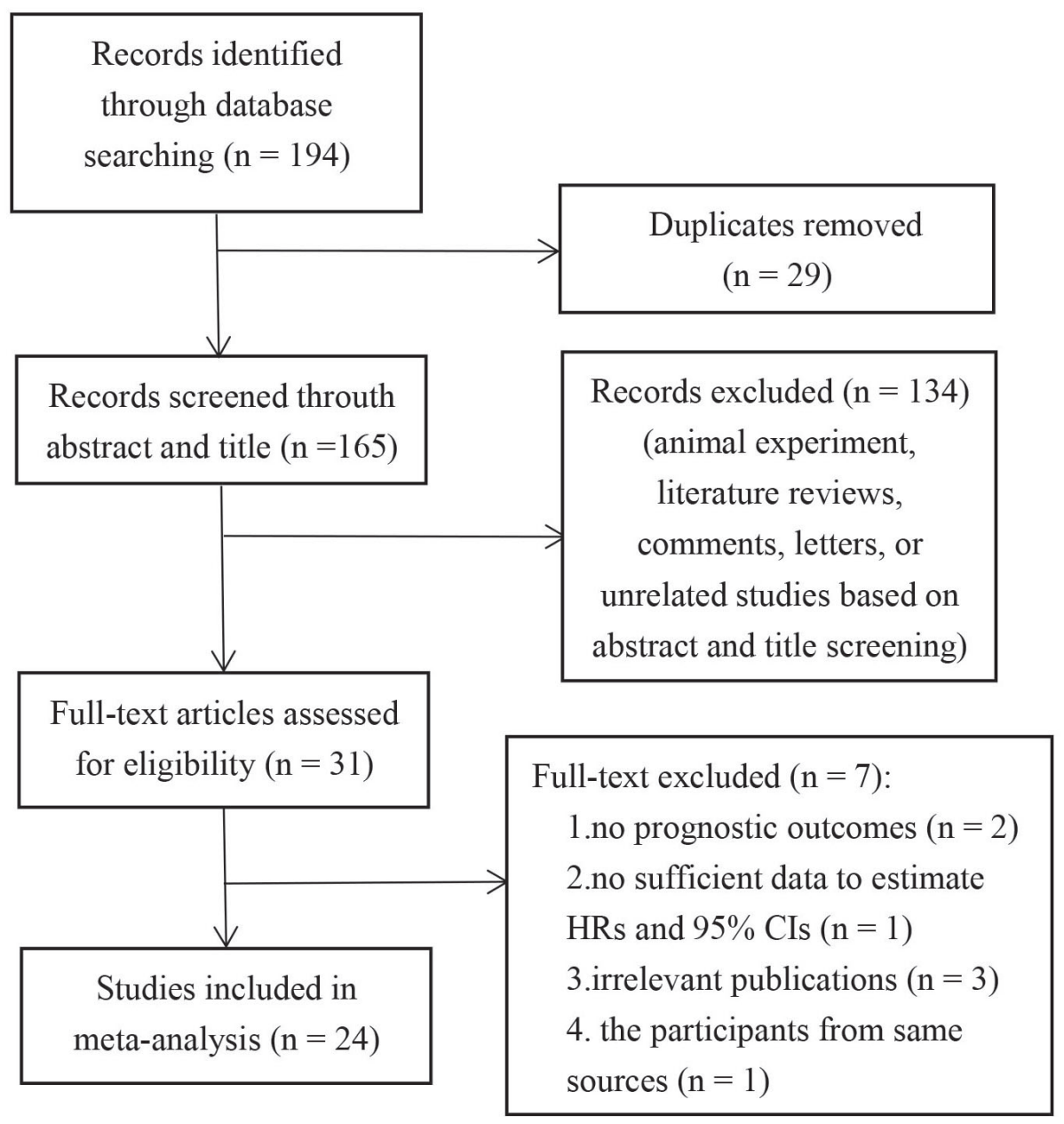

Figure 1: Flow chat of literature search and study selection. 
a

Study

ID

$\%$

$\mathrm{HR}(95 \% \mathrm{Cl}) \quad$ Weight

Azab (2014)

Baranyai(1) (2014)

Baranyai(2) (2014)

Carruthers (2012)

Chan (2016)

Choi (2015)

He (2013)

Kwon (2012)

Li (2016)

Li (2016)

Li (2015)

Neal (2015)

Neofytou (2014)

Passardi (2016)

Son (2013)

Song (2015)

Sun (2014)

Szkandera (2014)

Toiyama (2013)

Ying (2014)

You (2016)

Zou (2016)

Overall (I-squared $=58.6 \%, p=0.000)$

NOTE: Weights are from random effects analysis

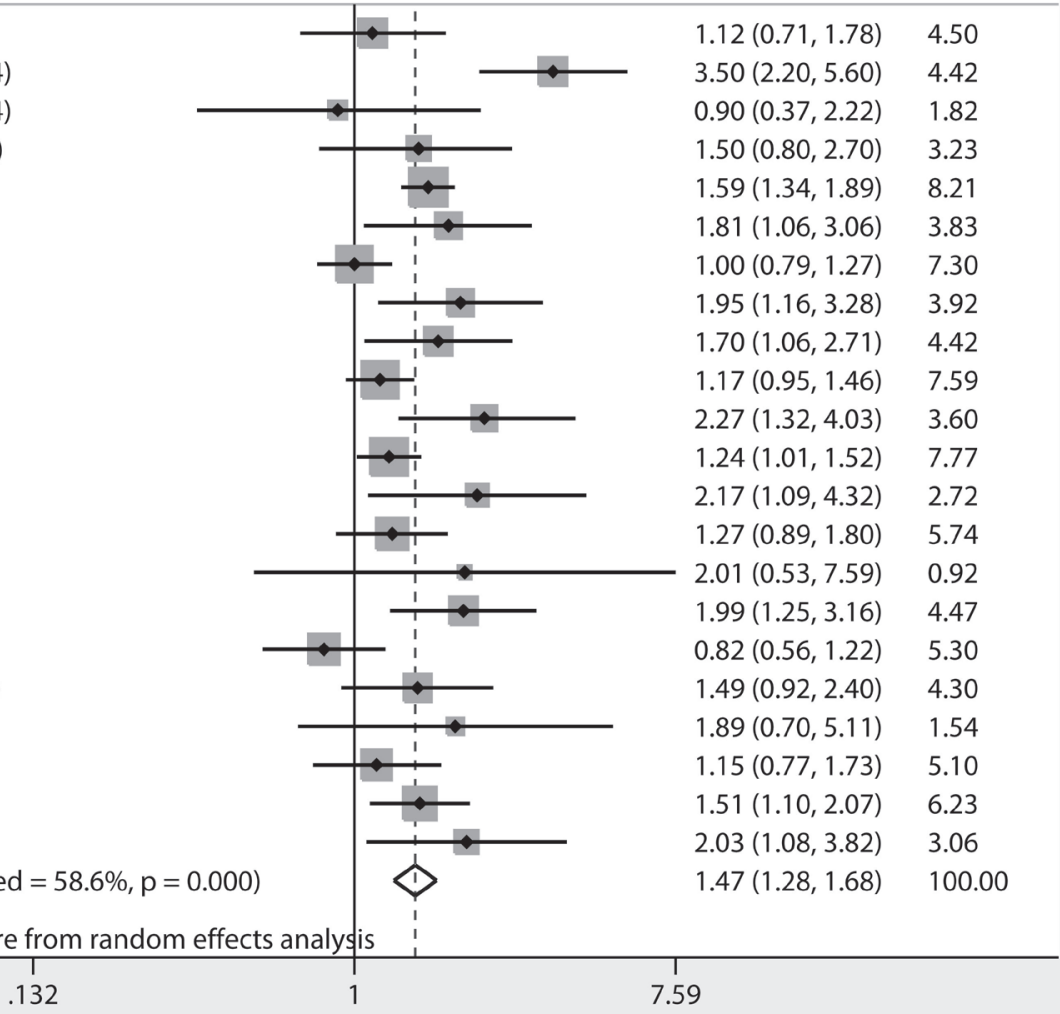

b

Study

ID

$\%$

HR $(95 \% \mathrm{Cl}) \quad$ Weight

Azab (2014)

Baranyai(1) (2014)

Carruthers (2012)

Li (2016)

Li (2016)

Mori (2015)

Neofytou (2014)

Ozawa (2015)

Son (2013)

Sun (2014)

Toiyama (2013)

Zou (2016)

Overall $(I-$ squared $=68.1 \%, p=0.000)$

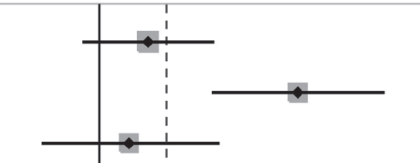

$1.35(0.90,2.03)$

10.18

$3.40(2.00,5.80) \quad 8.33$

$1.20(0.70,2.10) \quad 8.10$

$1.71(1.07,2.72) \quad 9.26$

$1.07(0.92,1.25) \quad 13.87$

$2.73(1.18,7.41) \quad 4.48$

$1.68(1.04,2.71) \quad 9.09$

$2.65(1.26,5.45) \quad 6.00$

$1.84(0.60,5.64) \quad 3.33$

$0.83(0.60,1.15) \quad 11.48$

$1.66(0.67,4.09) \quad 4.57$

$1.36(0.97,1.90) \quad 11.31$

$1.51(1.20,1.91) \quad 100.00$

NOTE: Weights are from random effects analysis

$$
\begin{array}{lll}
1 & 135 & 1 \\
& 1 & 7.41
\end{array}
$$

Figure 2: Results of prognostic analysis for PLR in CRC for OS a. and DFS b. 


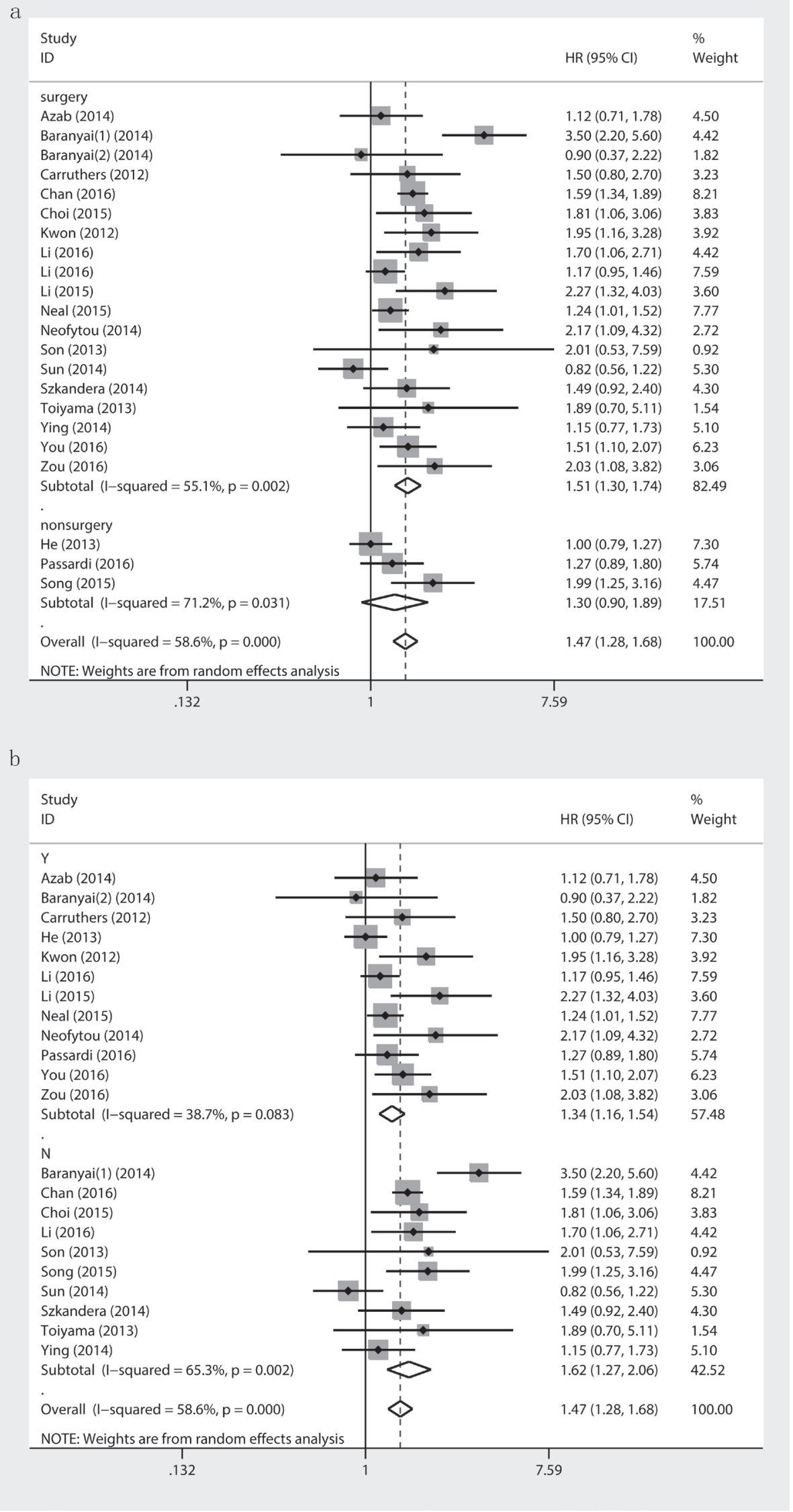

Figure 3: Association between PLR and OS stratified by treatment a., metastatic b. 


\section{Prognostic value of PLR for CRC patients}

Twenty-two studies containing 13328 CRC patients reported the impact of PLR on OS, which showed the existence of heterogeneity across the studies $\left(\mathrm{I}^{2}=58.6 \%\right.$, $\mathrm{Ph}<0.001)$. We detected that higher PLR predicate shorter OS for CRC patients (HR $=1.47 ; 95 \%$ CI, $1.28-1.68 ; p<$ 0.001)(Table 2, Figure 2a). Furthermore, twelve studies containing 8217 CRC patients suggested that elevated PLR was significantly associated with a poor DFS (HR = $1.51 ; 95 \%$ CI, 1.20-1.91; $p=0.001$ ) (Figure 2b). Increased PLR predicated a worse RFS (HR $=1.39 ; 95 \%$ CI, 1.03 $1.86 ; p=0.001)$ in the combination of 2 studies containing 754 CRC patients, however it was not related to CSS (HR $=1.14 ; 95 \%$ CI, 0.92-1.42; $p=0.223$ ) (Table 2) in the combination of four studies containing 881 CRC patients.

To explain the source of heterogeneity, we further performed a subgroup analysis by ethnicity, analysis method, major treatment therapy, respective cut-off value, sample size, metastasis status, tumor location and NOS score. The higher PLR was, the shorter OS and DFS were showed both in Caucasian ( [OS: HR $=1.6 ; 95 \%$ CI, 1.3 $1.96 ; p<0.001$ ]; [DFS: HR $=1.9 ; 95 \%$ CI, 1.06-3.4; $p=$
$0.031]$ ) and Asian groups ( [OS: HR $=1.41 ; 95 \% \mathrm{CI}, 1.17$ $1.7 ; p=0.001$ ]; [DFS: $\mathrm{HR}=1.37 ; 95 \% \mathrm{CI}, 1.06-1.78 ; p$ $=0.017])$. Significant association were detected whether univariate analysis ( [OS: $\mathrm{HR}=1.57$; 95\% CI, 1.26-1.96; $p<0.001$ ]; [DFS: $\mathrm{HR}=1.96 ; 95 \% \mathrm{CI}, 1.31-2.94 ; p=$ $0.011]$ ) or multivariate ( [OS: $\mathrm{HR}=1.32 ; 95 \% \mathrm{CI}, 1.17$ $1.48 ; p<0.001]$; [DFS: $\mathrm{HR}=1.27 ; 95 \% \mathrm{CI}, 1.02-1.6 ; p$ $=0.036]$ ) analysis were used in original studies. Elevated PLR was strongly associated with poor OS in patients who underwent surgical resection ( [OS: $\mathrm{HR}=1.51 ; 95 \%$ CI, 1.3-1.74; $p<0.001]$ ), but not in nonsurgery subgroup which involved limited studies ( [OS: HR $=1.31 ; 95 \%$ CI, 0.9-1.89; $p=0.157]$ ) (Figure 3a). After enlarging the sample size by meta-analysis, we overthrow the old conclusion in the negative study result subgroup that PLR had nothing to do with OS. For metastatic colorectal cancer patients, increased PLR predicated a worse OS and DFS ( [OS: HR $=1.34 ; 95 \%$ CI, 1.16-1.54; $p<0.001]$; [DFS: $\mathrm{HR}=1.17 ; 95 \% \mathrm{CI}, 1.04-1.33 ; p=0.012]$ ), and this prognostic implication also existed in nonmetastatic CRC ( [OS: HR $=1.62 ; 95 \%$ CI, 1.27-2.06; $p=0.001]$; [DFS: $\mathrm{HR}=1.89 ; 95 \% \mathrm{CI}, 1.15-3.08 ; p=0.011]$ ) (Figure 3b). Significant association were almost detected in all stratified analysis which further proved our results. More

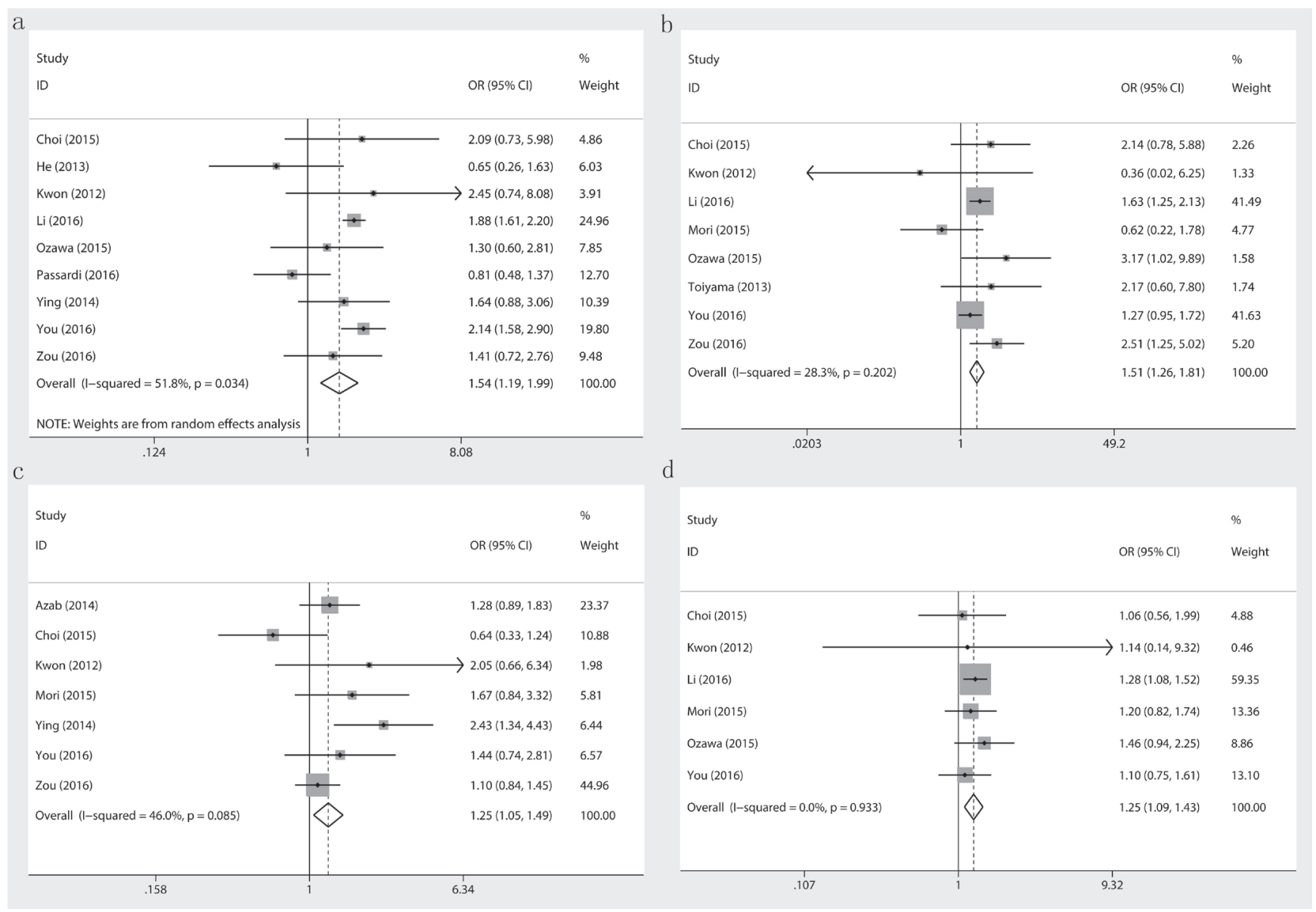

Figure 4: Association between PLR and tumor location a., differentiation b., stage c. and lymphovascular invasion d. 


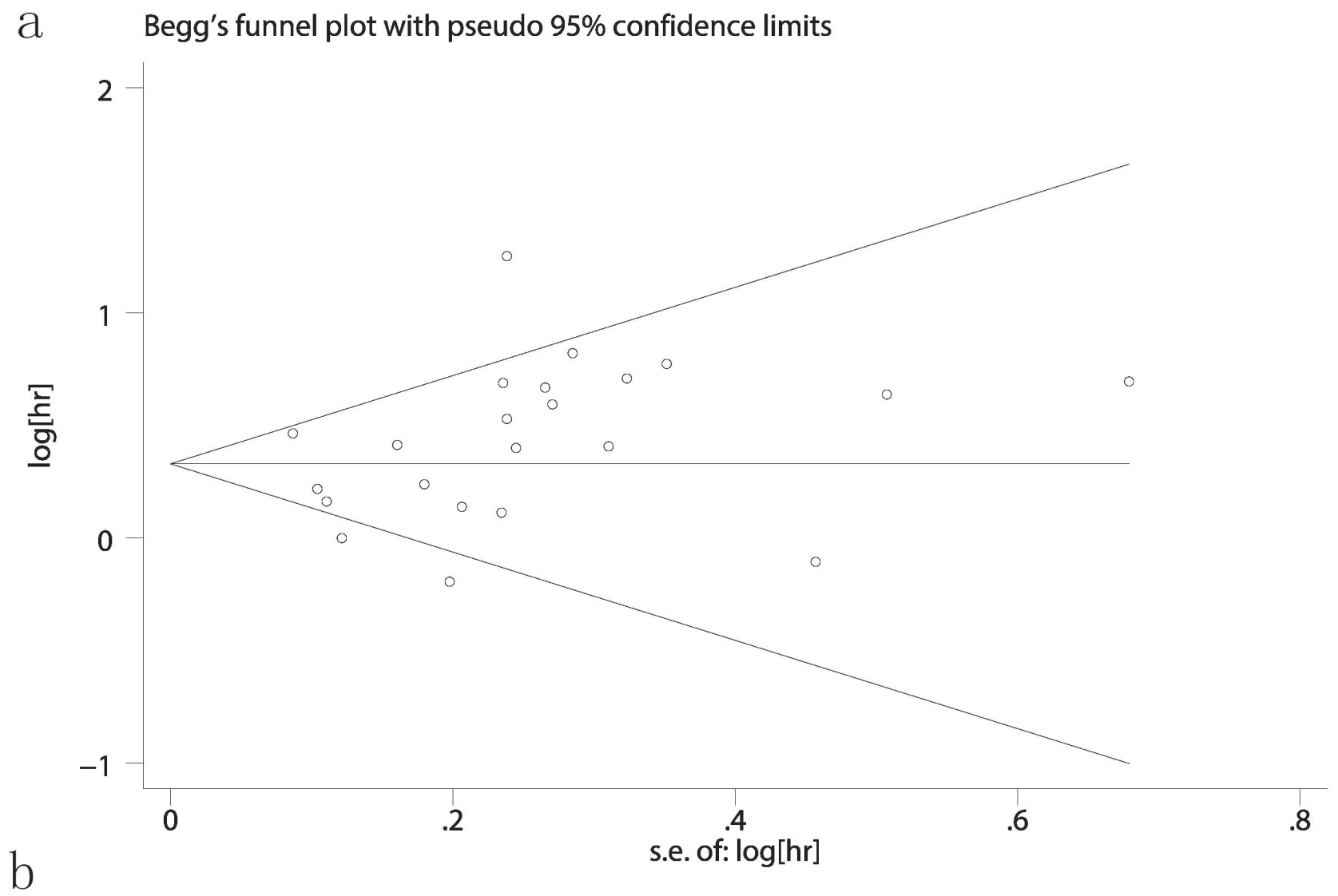

Filled funnel plot with pseudo $95 \%$ confidence limits

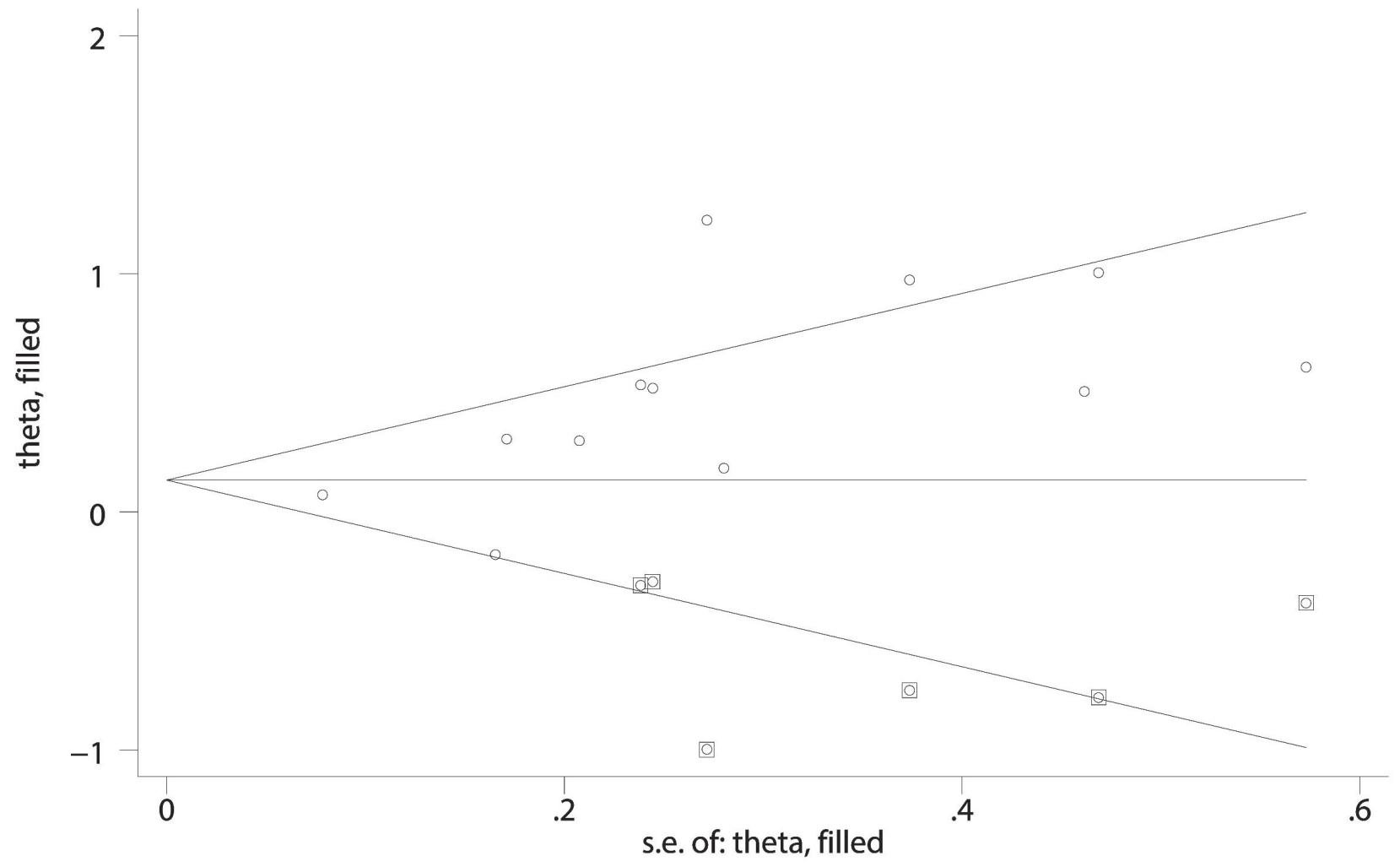

Figure 5: Egger's test for accessing publication biases for role of PLR on OS a. and DFS (b., after trim and fill method). 
Table 2: The pooled data on survival of meta-analysis

\begin{tabular}{|c|c|c|c|c|c|c|c|c|c|c|c|c|}
\hline \multirow{2}{*}{ Variables } & \multirow{2}{*}{$N^{\mathrm{a}}$} & \multirow{2}{*}{ Case $^{\mathrm{b}}$} & \multicolumn{2}{|c|}{ Pooled data } & \multicolumn{2}{|c|}{ Heterogeneity } & \multirow{2}{*}{$N^{\mathrm{a}}$} & \multirow{2}{*}{ Case $^{\mathrm{b}}$} & \multicolumn{2}{|c|}{ Pooled data } & \multicolumn{2}{|c|}{ Heterogeneity } \\
\hline & & & HR(95\%CI) & $P$ & $I^{2}$ & $P h$ & & & $\operatorname{HR}(95 \% C I)$ & $P$ & $I^{2}$ & $P h$ \\
\hline & \multicolumn{6}{|c|}{ Overall survival } & \multicolumn{6}{|c|}{ Disease-free survival } \\
\hline Overall & 22 & 13328 & $1.47(1.28,1.68)$ & $<0.001$ & $58.60 \%$ & $<0.001$ & 12 & 8217 & $1.51(1.2,1.91)$ & 0.001 & $68.10 \%$ & $<0.001$ \\
\hline \multicolumn{13}{|l|}{ By ethnicity } \\
\hline Caucasian & 9 & 3844 & $1.6(1.3,1.96)$ & $<0.001$ & $60.00 \%$ & 0.01 & 3 & 591 & $1.9(1.06,3.4)$ & 0.031 & $73.40 \%$ & 0.023 \\
\hline Asian & 12 & 8904 & $1.41(1.17,1.7)$ & 0.001 & $57.00 \%$ & 0.008 & 8 & 7046 & $1.37(1.06,1.78)$ & 0.017 & $60.80 \%$ & 0.013 \\
\hline Mixed & 1 & 580 & $1.12(0.71,1.77)$ & 0.629 & 1 & 1 & 1 & 580 & $1.35(0.9,2.03)$ & 0.148 & 1 & 1 \\
\hline \multicolumn{13}{|c|}{$\begin{array}{ll}\text { By } & \text { analysis } \\
\text { method } & \\
\end{array}$} \\
\hline Univariate & 10 & 3687 & $1.57(1.26,1.96)$ & $<0.001$ & $70.70 \%$ & $<0.001$ & 5 & 832 & $1.96(1.31,2.94)$ & 0.011 & $50.90 \%$ & 0.087 \\
\hline Multivariate & 12 & 9641 & $1.32(1.17,1.48)$ & $<0.001$ & $41.00 \%$ & 0.068 & 7 & 7385 & $1.27(1.02,1.6)$ & 0.036 & $57.50 \%$ & 0.028 \\
\hline \multicolumn{13}{|l|}{ By treatment } \\
\hline Surgery & 19 & 12619 & $1.51(1.3,1.74)$ & $<0.001$ & $55.1 \%$ & 0.002 & 12 & 8217 & $1.51(1.2,1.91)$ & 0.001 & $68.10 \%$ & $<0.001$ \\
\hline Non surgery & 3 & 709 & $1.31(0.9,1.89)$ & 0.157 & $71.2 \%$ & 0.031 & & & & & & \\
\hline \multicolumn{13}{|l|}{ By cut-off } \\
\hline Single cut-off & 15 & 10257 & $1.61(1.36,1.89)$ & $<0.001$ & $47.90 \%$ & 0.02 & 10 & 7382 & $1.69(1.28, \mathbf{2 . 2 2})$ & 0.001 & $67.70 \%$ & 0.001 \\
\hline Multiple cut-offs & 7 & 3071 & $1.27(1.03,1.56)$ & 0.026 & $62.50 \%$ & 0.014 & 2 & 835 & $1.04(0.65,1.67)$ & 0.856 & $69.50 \%$ & 0.07 \\
\hline$<200$ & 7 & 1043 & $1.50(1.24,1.81)$ & $<0.001$ & $3.40 \%$ & 0.4 & 6 & 870 & $1.72(1.34,2.2)$ & $<0.001$ & $<0.01 \%$ & 0.553 \\
\hline$\geq 200$ & 15 & 12245 & $1.44(1.22,1.71)$ & $<0.001$ & $68.10 \%$ & $<0.001$ & 6 & 7347 & $1.36(0.99,1.87)$ & 0.059 & $77.90 \%$ & $<0.001$ \\
\hline \multicolumn{13}{|l|}{ By sample size } \\
\hline$<200$ & 7 & 884 & $1.8(1.44,2.26)$ & $<0.001$ & $<0.01 \%$ & 0.698 & 5 & 636 & $1.62(1.2516,2.11)$ & $<0.001$ & $<0.01 \%$ & 0.653 \\
\hline$\geq 200$ & 15 & 12444 & $1.39(1.19,1.63)$ & $<0.001$ & $66.00 \%$ & $<0.001$ & 7 & 7581 & $1.46(1.06, \mathbf{2 . 0 1})$ & 0.019 & $78.10 \%$ & $<0.001$ \\
\hline \multicolumn{13}{|l|}{ By study result } \\
\hline Positive & 11 & 5007 & $1.57(1.41,1.74)$ & $<0.001$ & $12.80 \%$ & 0.325 & 5 & 887 & $1.65(1.32,2.05)$ & $<0.001$ & $2.50 \%$ & 0.392 \\
\hline Negative & 11 & 8221 & $1.29(1.05,1.59)$ & 0.016 & $62.50 \%$ & 0.002 & 7 & 7330 & $1.36(0.99,1.87)$ & 0.058 & $73.20 \%$ & 0.001 \\
\hline \multicolumn{13}{|l|}{ By metastatic } \\
\hline Yes & 12 & 8963 & $1.34(1.16,1.54)$ & $<0.001$ & $38.70 \%$ & 0.083 & 5 & 6387 & $1.17(1.04,1.33)$ & 0.012 & $13.80 \%$ & 0.327 \\
\hline No & 10 & 4365 & $1.62(1.27,2.06)$ & 0.001 & $65.30 \%$ & 0.002 & 7 & 1830 & $1.89(1.15,3.08)$ & 0.011 & $77.00 \%$ & $<0.001$ \\
\hline \multicolumn{13}{|l|}{ By location } \\
\hline Colorectal cancer & 15 & 11628 & $1.47(1.26,1.71)$ & $<0.001$ & $64.40 \%$ & $<0.001$ & 7 & 6999 & $1.71(1.23,2.37)$ & 0.001 & $76.80 \%$ & $<0.001$ \\
\hline Rectal cancer & 3 & 339 & $1.65(1.17,2.34)$ & 0.005 & $<0.01 \%$ & 0.914 & 3 & 339 & $1.5(1.07,2.08)$ & 0.017 & $<0.01 \%$ & 0.615 \\
\hline Colon cancer & 4 & 1361 & $1.49(0.92,2.4)$ & 0.183 & $69.40 \%$ & 0.02 & 2 & 879 & $0.89(0.65,1.21)$ & 0.45 & $42.70 \%$ & 0.186 \\
\hline \multicolumn{13}{|l|}{ By NOS } \\
\hline$<6$ & 3 & 631 & $2.02(1.06,3.87)$ & 0.034 & $74.00 \%$ & 0.021 & 1 & 336 & $3.4(2.0,5.79)$ & $<0.001$ & 1 & 1 \\
\hline \multirow[t]{2}{*}{$\geq 6$} & 19 & 12597 & $1.34(1.24,1.45)$ & $<0.001$ & $43.50 \%$ & 0.023 & 11 & 7881 & $1.35(1.11, \mathbf{1 . 6 5})$ & 0.002 & $50.90 \%$ & 0.026 \\
\hline & \multicolumn{6}{|c|}{ Cancer-specific survival } & \multicolumn{6}{|c|}{ Recurrence-free survival } \\
\hline Overall & 4 & 881 & $1.14(0.92,1.42)$ & 0.223 & $63.70 \%$ & 0.041 & 2 & 754 & $1.39(1.03,1.86)$ & 0.03 & $13.50 \%$ & 0.282 \\
\hline
\end{tabular}

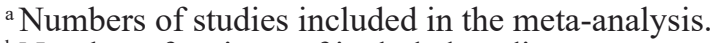

${ }^{b}$ Number of patients of included studies.

Abbreviations: NA: not available; HR: hazard ratio; 95\%CI: confidence interval; $P$ : $p$ value of pooled HR; $P$ : value of Higgins

I-squared statistics; $P h: p$ value of Heterogeneity test.

details about the subgroup analysis of OS and DFS were presented in Table 2 .

\section{PLR and clinical characteristics of CRC patients}

In addition, we examined the association between PLR and the clinical parameters of colorectal cancer (Table 3). Peripheral higher PLR was detected to be associated with gender $(\mathrm{OR}=0.8 ; 95 \% \mathrm{CI}, 0.72-0.90 ; p$ $<0.001)$, cancer location $(\mathrm{OR}=1.54 ; 95 \% \mathrm{CI}, 1.19-1.99$; $p=0.001)$, poorer differentiation status $(\mathrm{OR}=1.51 ; 95 \%$ CI, 1.26-1.81; $p<0.001)$, higher tumor stage(OR $=1.25$;
$95 \% \mathrm{CI}, 1.05-1.49 ; p=0.012)$, higher $\mathrm{T}(\mathrm{OR}=2.13 ; 95 \%$ $\mathrm{CI}, 1.36-3.34 ; p=0.001)$ stage and $\mathrm{N}$ stage $(\mathrm{OR}=1.35$; 95\% CI, 1.17-1.54; $p<0.001)$, more lymphovascular invasion $(\mathrm{OR}=1.25 ; 95 \% \mathrm{CI}, 1.09-1.43 ; p=0.001)$, and recurrence $(\mathrm{OR}=2.78 ; 95 \% \mathrm{CI}, 1.36-5.68 ; p=0.005)$ in colorectal cancer patients (Figure 4).

\section{Sensitivity analysis and publication bias}

To identify the source of heterogeneity across selected studies, sensitivity analysis was conducted by removing each study in turn from the analysis. The pooled 
Table 3: The pooled data on clinical characteristics of included studies

\begin{tabular}{|c|c|c|c|c|c|c|}
\hline \multirow{2}{*}{ Variables } & \multirow{2}{*}{$N^{\mathrm{a}}$} & \multirow{2}{*}{ Case $^{\mathrm{b}}$} & \multicolumn{2}{|c|}{ Pooled data } & \multicolumn{2}{|c|}{ Heterogeneity } \\
\hline & & & OR(95\%CI) & $\boldsymbol{P}$ & $I^{2}$ & $P h$ \\
\hline Gender & 13 & 9483 & & & & \\
\hline Female & & 3908 & Reference & & & \\
\hline Male & & 5575 & $0.8(0.72,0.90)$ & $<0.001$ & $<0.01 \%$ & 0.512 \\
\hline Location & 9 & 8262 & & & & \\
\hline Rectaum & & 4261 & Reference & & & \\
\hline Colon & & 4001 & $1.54(1.19,1.99)$ & 0.001 & $51.80 \%$ & 0.034 \\
\hline Differentiation & 8 & 7388 & & & & \\
\hline Well and moderately & & 6526 & Reference & & & \\
\hline Poorly & & 862 & $1.51(1.26,1.81)$ & $<0.001$ & $28.30 \%$ & 0.202 \\
\hline Stage & 7 & 3156 & & & & \\
\hline $\mathrm{I} / \mathrm{II}$ & & 1770 & Reference & & & \\
\hline III/IV & & 1386 & $1.25(1.05,1.49)$ & 0.012 & $46.00 \%$ & 0.085 \\
\hline$T$ & 7 & 6419 & & & & \\
\hline 1,2 & & 1516 & Reference & & & \\
\hline 3,4 & & 4903 & $2.13(1.36,3.34)$ & 0.001 & $51.10 \%$ & 0.056 \\
\hline $\mathbf{N}$ & 6 & 6583 & & & & \\
\hline Negative(N0) & & 3504 & Reference & & & \\
\hline Positive(N1,2) & & 3079 & $1.35(1.17,1.54)$ & $<0.001$ & $22.80 \%$ & 0.262 \\
\hline $\begin{array}{l}\text { LVI(lymphovascular } \\
\text { invasion) }\end{array}$ & 6 & 7951 & & & & \\
\hline No & & 5733 & Reference & & & \\
\hline Yes & & 2218 & $1.25(1.09,1.43)$ & 0.001 & $<0.01 \%$ & 0.933 \\
\hline Recurrence & 2 & 236 & & & & \\
\hline Absent & & 192 & Reference & & & \\
\hline Present & & 44 & $2.78(1.36,5.68)$ & 0.005 & $<0.01 \%$ & 0.352 \\
\hline Chemotherapy & 4 & 6670 & & & & \\
\hline No & & 2214 & Reference & & & \\
\hline Yes & & 4456 & $1.09(0.74,1.61)$ & 0.674 & $72.00 \%$ & 0.013 \\
\hline
\end{tabular}

${ }^{a}$ Numbers of studies included in the meta-analysis.

${ }^{\mathrm{b}}$ Number of patients of included studies.

Abbreviations: LVI: lymphovascular invasion; OR: odds ratio; 95\%CI: confidence interval; $P$ : $p$ value of pooled HR; $I^{2}$ : value of $X^{2}$ based I-squared statistics; $P h: p$ value of Heterogeneity test.

ORs and HRs were not significantly changed, indicating the stability of our analyses. The funnel plots were largely symmetrical for OS in patients with CRC, and the results of the Begg's and Egger's tests showed no evidence of significant publication bias among the included studies (OS: Begg's test $\operatorname{Pr}>|z|=0.159$, Egger's test $P>|\mathrm{t}|=$ 0.130 ) (Figure 5a). But slight publication bias was seen in DFS (DFS: Begg's test $\operatorname{Pr}>|\mathrm{z}|=0.064$, Egger's test $P>$ $|t|=0.013)$. So a trim and fill method was used to estimate the asymmetry in the funnel plot $(\mathrm{HR}=1.143 ; 95 \% \mathrm{CI}$, 0.903-1.447, $p=0.267$ )(Figure 5b).

\section{DISCUSSION}

This systematic review and meta-analysis, including 24 individual studies of 13719 patients, found that increased PLR was strongly associated with poor overall survival and recurrence-free survival in patient with colorectal cancer. However, PLR was unrelated to cancerspecific survival and disease-free survival after trim and fill method. The stratified analyses showed that elevated PLR was associated with poor outcome in both Caucasian and Asian population, univariate and multivariate analysis, metastatic and nonmetastatic $\mathrm{CRC}$, and resected patients. However, we did not observe the significant association in nonsurgery subgroup for that the number of the included original studies in this subgroup is limited. For the negative study result subgroup, the HR of OS was 1.29 (95\% CI, 1.05-1.59; $p=0.016)$, which meaned that after enlarging the sample size by meta-analysis, we overthrow the old conclusion that PLR had nothing to do with OS. Our finding confirmed the hypothesis that PLR was an appropriate prognostic factor for CRC patient survival.

Cancer progression and prognosis was determined not only by tumor characteristics but also by the 
host inflammatory response [44, 45]. Using clinical, inflammatory, and molecular biomarkers as CRC prognostic factors are increasingly interesting, but there remained a lack of reliable, reproducible, and low-cost markers that can be readily incorporated into routine practice to optimally predict prognosis and guide treatment [31]. Some combinations of the inflammatory response parameters (eg. lymphocytes, neutrophils, platelets and acute-phase proteins, which are simple and easy to measure using standardized and widely used assays) including platelet-to-lymphocyte ratio (PLR), neutrophil-to-lymphocyte ratio (NLR), lymphocyteto-monocyte ratio (LMR) and albumin/globulin ratio (AGR), have been performed to evaluate the prognosis in various cancers, including CRC, and so on [27, 33, 46-48]. There were many reasons for PLR's ideal prognostic role in CRC patient. Firstly, platelets secrete several tumor growth and angiogenic factors, which might influence tumor progression [49]. Secondly, while in antitumor reaction of the immune system, the CD8+ and CD4+ T-lymphocyte interaction among each other can induce tumor cell apoptosis, which can improve the survival of CRC patients for the chemotherapy efficacy [50]. These supported our finding that the PLR was a promising prognostic factors for the survival of CRC patients, which was consistent with previous meta-analysis [51-54], however, our study was to some extent superior to the previous studies because of much more included studied and patients, more detailed analyses and less limitation. We included all current eligible relative studies by systemic review and meta-analysis. We did subgroup analyses to explore the heterogeneity sources, besides we explored the relationship between PLR and the inferior clinical features.

By analyzing clinical factors, we found the relationship between the increased PLR and the clinical characteristics of CRC patients. PLR tended to be higher in colon cancer than rectum which need further explanation. Poorly differentiated cancer always accompanied with elevated PLR, for that poorly differentiated tumour cells growing faster with angiogenic and tumour growth factors secreted by platelet cell, such as platelet factor 4 (PF4), thrombospondin, vascular endothelial growth factor (VEGF), transforming growth factor beta (TGF- $\beta$ ) and platelet-derived growth factor (PDGF) [36]. Moreover, platelets reflected the invasive potential of CRC and was closely associated with lymphovascular invasion (LVI) [55]. PLR was a good prognostic marker in mCRC patients, because several studies have shown that platelets induce circulating tumor cell epithelialmesenchymal transition and promote extravasation to metastatic sites [43, 56, 57]. Lymphocytes were involved in cancer immune surveillance which influenced the tumor recurrence to some extent [58]. Our study results indicated that the relationship between PLR and some clinical factors presented a new researching direction for future research. Moreover, the easily got PLR can be used to reflect some clinical characteristics which were difficult to obtain like tumour differentiation, lymphovascular invasion (LVI), recurrence and so on. Pretreatment blood test for PLR played a vital role in assessment of cancer characteristics and patients prognosis.

There were limitations in our systematic review. First, the included studies were almost retrospective studies and more studies with prospective design were warranted in future. Second, eleven enrolled studies applied univariate analysis only (without providing multivariate analysis data), while subgroup analysis showed the prognostic values of PLR existed in these studies. Moreover, there are significant heterogeneity existing in OS and DFS analysis. Therefore additional large cohorts of prospective studies are needed to correct for heterogeneity.

In conclusion, peripheral blood PLR was an effective prognostic marker for CRC patients. Elevated PLR was related to worse overall survival and recurrencefree survival, but not for disease-free survival and cancerspecific survival. The prognostic utility of PLR might help to guide use of individual therapies and patient counselling in future.

\section{MATERIALS AND METHODS}

\section{Search strategy}

PubMed, Web of Science and Embase were searched from inception to September 2016. The search strategy used the keywords as follows: "PLR" or "platelet lymphocyte ratio" or "platelet to lymphocyte ratio" or "platelet-lymphocyte ratio" or "platelet lymphocyte" and "CRC" or "colon neoplasm" or "rectal neoplasm" or "colorectal neoplasm" or "colorectal tumor" or "colorectal cancer" or "colorectal carcinoma". There was no language restriction in our study. References of relevant studies and review articles were searched for potential eligible studies.

\section{Inclusion and exclusion criteria}

The inclusion criteria in this meta-analysis study were as follows: (1) studies investigated the relationship between PLR and colorectal cancer prognosis or clinical characteristics; (2) the PLR was obtained from a preoperative peripheral blood test; (3) adequate data were provided to measure odds ratio (OR) and hazard ratios (HRs) with 95\% confidence intervals (CIs). The exclusion criteria were as follows: (1) unrelated studies, animal experiment, cell experiment, literature reviews, comments, letters, meta analysis, or case reports; (2) studies without sufficient data for analysis; and (3) duplicated publications. When studies with overlapping cases were met, the study with the larger number of patients was included. 


\section{Data collection and quality assessment}

Relevant datas were professionally extracted by two authors independently, and disagreements were resolved through discussion with a third author. Data collected from each study included first author, publication year, country and ethnicity of the study participants, number of patients, tumor characteristics (stage, location, size, differentiation, lymphovascular invasion, treatment, recurrence), cut off value for high or low PLR, and survival data (OS/DFS/ CSS/RFS). If some publications provided survival data by Kaplan-Meier curves indirectly, Engauge Digitizer version 4.1 was applied to extract the data. The quality of included articles were assessed using the NewcastleOttawa Scale (NOS) by two authors independently (Supplementary Table S2 showed the Newcastle-Ottawa quality assessment scale). The total scores of NOS ranged from 0 to 9 , with higher scores indicating better quality. A high-quality study was defined as the study with $\geq 6$ points on NOS.

\section{Statistical analysis}

According to the cut-off values, PLR was devided into high or low level groups in each study, and the hazard ratio with the $95 \%$ confidence interval (high vs low level of PLR) were used to evaluate the relationship between PLR and long-term prognosis (OS/DFS/CSS/ RFS). Odds ratio and $95 \% \mathrm{CI}$ were pooled to access the role of PLR on clinical features of colorectal cancer. Statistical heterogeneity was evaluated by $\mathrm{Q}$ and $\mathrm{I}^{2}$ tests, and if the $p$-value $<0.1$ or $\mathrm{I}^{2}>50 \%$, which suggested the existence of substantial heterogeneity, thus we used a random-effect model to calculate the pooled estimate. Otherwise, the fixed-effect model would be applied instead. The subgroup analyses were applied to explore the heterogeneity sources. Publication bias was evaluated using the Egger's weighted linear regression and Begg's regression method. A trim and fill method was used when significant publication bias existed. All statistical tests were two-sided, and a $p$ value $<0.05$ was considered to be statistically significant. All analyses were conducted by Stata 14.0 (STATA Corporation, College Station, TX, USA).

\section{Abbreviations}

CRC, colorectal cancer; PLR, platelet-lymphocyte ratio; $\mathrm{HR}$, hazard ratio; OR, odds ratio; $95 \% \mathrm{CI}, 95 \%$ confidence interval; OS, overall survival; DFS, diseasefree survival; RFS, recurrence-free survival; CSS, Cancerspecific survival; NOS, the Newcastle-Ottawa Scale; $\mathrm{Ph}$, $\mathrm{P}$-value of heterogeneity.

\section{Authors' contributions}

N. C., WL. L. and M. Q. conceived the study idea and designed the study. KX. H. and WH. Y. reviewed the literature and Collected the data. L.H. performed statistical analyses. N. C., and WL. L. drafted the manuscript. TX. C. and QF. L. reviewed and edited the manuscript. All authors read and approved the final manuscript.

\section{CONFLICTS OF INTERESTS}

The authors have declared no conflict of financial interest.

\section{REFERENCES}

1. Brody H. Colorectal cancer. Nature. 2015; 521: S1

2. Torre LA, Bray F, Siegel RL, Ferlay J, Lortet-Tieulent J, Jemal A. Global cancer statistics, 2012. CA Cancer J Clin. 2015; 65: 87-108.

3. Brenner H, Kloor M, Pox CP. Colorectal cancer. Lancet. 2014; 383: 1490-1502.

4. Yu H, Luo Y, Wang X, Bai L, Huang P, Wang L, Huang M, Deng Y, Wang J. Time to lowest postoperative carcinoembryonic antigen level is predictive on survival outcome in rectal cancer. Sci Rep. 2016; 6: 34131.

5. Bosetti C, Bertuccio P, Malvezzi M, Levi F, Chatenoud L, Negri E, La Vecchia C. Cancer mortality in Europe, 20052009, and an overview of trends since 1980. Ann Oncol. 2013; 24: 2657-2671.

6. Chatenoud L, Bertuccio P, Bosetti C, Malvezzi M, Levi F, Negri E, La Vecchia C. Trends in mortality from major cancers in the Americas: 1980-2010. Ann Oncol. 2014; 25: 1843-1853.

7. Szkandera J, Pichler M, Absenger G, Stotz M, Arminger F, Weissmueller M, Schaberl-Moser R, Samonigg H, Kornprat P, Stojakovic T, Avian A, Gerger A. The elevated preoperative platelet to lymphocyte ratio predicts decreased time to recurrence in colon cancer patients. Am J Surg. 2014; 208: 210-214.

8. Lenos K, Goos JA, Vuist IM, den Uil SH, Delis-van Diemen PM, Belt EJ, Stockmann HB, Bril H, de Wit M, Carvalho B, Giblett S, Pritchard CA, Meijer GA, et al. MGL ligand expression is correlated to BRAF mutation and associated with poor survival of stage III colon cancer patients. Oncotarget. 2015; 6: 26278-26290. doi: 10.18632/ oncotarget. 4495 .

9. Vincenzi B, Cremolini C, Sartore-Bianchi A, Russo A, Mannavola F, Perrone G, Pantano F, Loupakis F, Rossini D, Ongaro E, Bonazzina E, Dell'Aquila E, Imperatori M, et al. Prognostic significance of K-Ras mutation rate in metastatic colorectal cancer patients. Oncotarget. 2015; 6: 31604-31612. 2015; 6: 31604-31612. doi: 10.18632/ oncotarget.5231. 
10. Spindler KL, Christensen IJ, Nielsen HJ, Jakobsen A, Brünner N. TIMP-1 and CEA as biomarkers in third-line treatment with irinotecan and cetuximab for metastatic colorectal cancer. Tumour Biol. 2015; 36: 4301-4308.

11. Calon A, Lonardo E, Berenguer-Llergo A, Espinet E, Hernando-Momblona X, Iglesias M, Sevillano M, PalomoPonce S, Tauriello DV, Byrom D, Cortina C, Morral C, Barceló C, et al. Stromal gene expression defines poorprognosis subtypes in colorectal cancer. Nat Genet. 2015; 47: 320-329.

12. Moreno V, Sanz-Pamplona R. Altered pathways and colorectal cancer prognosis [Commentary]. BMC Med. 2015; $13: 76$.

13. Salazar R, Roepman P, Capella G, Moreno V, Simon I, Dreezen C, Lopez-Doriga A, Santos C, Marijnen C, Westerga J, Bruin S, Kerr D, Kuppen P, et al. Gene expression signature to improve prognosis prediction of stage II and III colorectal cancer. J Clin Oncol. 2011; 29: 17-24.

14. Roth AD, Tejpar S, Delorenzi M, Yan P, Fiocca R, Klingbiel D, Dietrich D, Biesmans B, Bodoky G, Barone C, Aranda E, Nordlinger B, Cisar L, et al. Prognostic role of KRAS and BRAF in stage II and III resected colon cancer: results of the translational study on the PETACC-3, EORTC 40993, SAKK 60-00 trial. J Clin Oncol. 2010; 28: 466-474.

15. Grivennikov SI, Greten FR, Karin M. Immunity, inflammation, and cancer. Cell. 2010; 140: 883-899.

16. Templeton AJ, Ace O, McNamara MG, Al-Mubarak M, Vera-Badillo FE, Hermanns T, Seruga B, Ocaña A, Tannock IF, Amir E. Prognostic role of platelet to lymphocyte ratio in solid tumors: a systematic review and meta-analysis. Cancer Epidemiol Biomarkers Prev. 2014; 23: 1204-1212.

17. Grivennikov SI, Greten FR, Karin M. Immunity, inflammation, and cancer. Cell. 2010; 140: 883-899.

18. Mantovani A, Allavena P, Sica A, Balkwill F. Cancerrelated inflammation. Nature. 2008 Jul 24; 454: 436-444.

19. Balkwill F, Mantovani A. Inflammation and cancer: back to Virchow? Lancet. 2001; 357: 539-545.

20. Choi WJ, Cleghorn MC, Jiang H, Jackson TD, Okrainec A, Quereshy FA. Preoperative Neutrophil-to-Lymphocyte Ratio is a Better Prognostic Serum Biomarker than Plateletto-Lymphocyte Ratio in Patients Undergoing Resection for Nonmetastatic Colorectal Cancer. Ann Surg Oncol. 2015; 22(suppl 3): S603-S613.

21. Kwon HC, Kim SH, Oh SY, Lee S, Lee JH, Choi HJ, Park KJ, Roh MS, Kim SG, Kim HJ, Lee JH. Clinical significance of preoperative neutrophil-lymphocyte versus platelet-lymphocyte ratio in patients with operable colorectal cancer. Biomarkers. 2012; 17: 216-222.

22. Li ZM, Peng YF, Du CZ, Gu J. Colon cancer with unresectable synchronous metastases: the AAAP scoring system for predicting the outcome after primary tumour resection. Colorectal Dis. 2016; 18: 255-263.
23. Mori K, Toiyama Y, Saigusa S, Fujikawa H, Hiro J, Kobayashi M, Ohi M, Araki T, Inoue Y, Tanaka K, Mohri Y, Kusunoki M. Systemic analysis of predictive biomarkers for recurrence in colorectal cancer patients treated with curative surgery. Dig Dis Sci 2015; 60: 2477-2487.

24. Neal CP, Cairns V, Jones MJ, Masood MM, Nana GR, Mann CD, Garcea G, Dennison AR. Prognostic performance of inflammation-based prognostic indices in patients with resectable colorectal liver metastases. MedOncol. 2015; 32: 144.

25. Neofytou K, Smyth EC, Giakoustidis A, Khan AZ, Williams R, Cunningham D, Mudan S. The Preoperative Lymphocyte-to-Monocyte Ratio is Prognostic of Clinical Outcomes for Patients with Liver-Only Colorectal Metastases in the Neoadjuvant Setting. Ann Surg Oncol. 2015; 22: 4353-4362.

26. Neofytou K, Smyth EC, Giakoustidis A, Khan AZ, Cunningham D, Mudan S. Elevated platelet to lymphocyte ratio predicts poor prognosis after hepatectomy for liveronly colorectal metastases, and it is superior to neutrophil to lymphocyte ratio as an adverse prognostic factor. Med Oncol. 2014; 31: 239.

27. Ozawa T, Ishihara S, Nishikawa T, Tanaka T, Tanaka J, Kiyomatsu T, Hata K, Kawai K, Nozawa H, Kazama S, Yamaguchi H, Sunami E, Kitayama J, et al. The preoperative platelet to lymphocyte ratio is a prognostic marker in patients with stage II colorectal cancer. Int $\mathbf{J}$ Colorectal Dis. 2015; 30: 1165-1171.

28. Zou ZY, Liu HL, Ning N, Li SY, DU XH, Li R. Clinical significance of pre-operative neutrophil lymphocyte ratio and platelet lymphocyte ratio as prognostic factors for patients with colorectal cancer. Oncol Lett. 2016; 11: 22412248.

29. You J, Zhu GQ, Xie L, Liu WY, Shi L, Wang OC, Huang ZH, Braddock M, Guo GL, Zheng MH. Preoperative platelet to lymphocyte ratio is a valuable prognostic biomarker in patients with colorectal cancer. Oncotarget. 2016; 7:25516-27. doi: 10.18632/oncotarget.8334.

30. Song A, Eo W, Lee S. Comparison of selected inflammation-based prognostic markers in relapsed or refractory metastatic colorectal cancer patients. World J Gastroenterol. 2015; 21: 12410-12420.

31. Chan JC, Chan DL, Diakos CI, Engel A, Pavlakis N, Gill A, Clarke SJ. The Lymphocyte-to-Monocyte Ratio is a Superior Predictor of Overall Survival in Comparison to Established Biomarkers of Resectable Colorectal Cancer. Ann Surg. In press 2016.

32. Li H, Song J, Cao M, Wang G, Li L, Zhang B, Li Y, Xu W, Zheng J. Preoperative neutrophil-to-lymphocyte ratio is a more valuable prognostic factor than platelet-to-lymphocyte ratio for nonmetastatic rectal cancer. Int Immunopharmacol. 2016; 40: 327-331.

33. Azab B, Mohammad F, Shah N, Vonfrolio S, Lu W, Kedia $\mathrm{S}$, Bloom SW.The value of the pretreatment neutrophil lymphocyte ratio vs. platelet lymphocyte ratio in predicting 
the long-term survival in colorectal cancer. Cancer Biomark. 2014; 14: 303-312.

34. Baranyai Z, Krzystanek M, Josa V, Dede K, Agoston E, Szász AM, Sinkó D, Szarvas V, Salamon F, Eklund AC, Szállási Z, Jakab F The comparison of thrombocytosis and platelet-lymphocyte ratio as potential prognostic markers in colorectal cancer. Thromb Haemost. 2014; 111: 483-90.

35. Carruthers R, Tho LM, Brown J, Kakumanu S, McCartney $\mathrm{E}, \mathrm{McDonald}$ AC. Systemic inflammatory response is a predictor of outcome in patients undergoing preoperative chemoradiation for locally advanced rectal cancer. Colorectal Dis. 2012; 14: e701-e707.

36. He W, Yin C, Guo G, Jiang C, Wang F, Qiu H, Chen X, Rong R, Zhang B, Xia L. Initial neutrophil lymphocyte ratio is superior to platelet lymphocyte ratio as an adverse prognostic and predictive factor in metastatic colorectal cancer. Med Oncol. 2013; 30: 439.

37. Son HJ, Park JW, Chang HJ, Kim DY, Kim BC, Kim SY, Park SC, Choi HS, Oh JH. Preoperative plasma hyperfibrinogenemia is predictive of poor prognosis in patients with nonmetastatic colon cancer. Ann Surg Oncol. 2013; 20: 2908-2913.

38. Sun ZQ, Han XN, Wang HJ, Tang Y, Zhao ZL, Qu YL, $\mathrm{Xu}$ RW, Liu YY, Yu XB. Prognostic significance of preoperative fibrinogen in patients with colon cancer. World J Gastroenterol. 2014; 20: 8583-8591.

39. Szkandera J, Pichler M, Absenger G, Stotz M, Arminger F, Weissmueller M, Schaberl-Moser R, Samonigg H, Kornprat P, Stojakovic T, Avian A, Gerger A. The elevated preoperative platelet to lymphocyte ratio predicts decreased time to recurrence in colon cancer patients. Am J Surg. 2014; 208: 210-214.

40. Toiyama Y, Inoue Y, Saigusa S, Kawamura M, Kawamoto A, Okugawa Y, Hiro J, Tanaka K, Mohri Y, Kusunoki M. $\mathrm{C}$-reactive protein as predictor of recurrence in patients with rectal cancer undergoing chemoradiotherapy followed by surgery. Anticancer Res. 2013; 33: 5065-5074.

41. Ying HQ, Deng QW, He BS, Pan YQ, Wang F, Sun HL, Chen J, Liu X, Wang SK. The prognostic value of preoperative NLR, d-NLR, PLR and LMR for predicting clinical outcome in surgical colorectal cancer patients. Med Oncol. 2014; 31: 305.

42. Li Y, Jia H, Yu W, Xu Y, Li X, Li Q, Cai S. Nomograms for predicting prognostic value of inflammatory biomarkers in colorectal cancer patients after radical resection. Int $\mathbf{J}$ Cancer. 2016; 139: 220-231.

43. Passardi A, Scarpi E, Cavanna L, Dall'Agata M, Tassinari D, Leo S, Bernardini I, Gelsomino F, Tamberi S, Brandes AA, Tenti E, Vespignani R, Frassineti GL, et al. Inflammatory indexes as predictors of prognosis and bevacizumab efficacy in patients with metastatic colorectal cancer. Oncotarget. 2016; 7: 33210-33219. 2016; 7:332109. doi: 10.18632/oncotarget.8901.
44. Mantovani A, Allavena P, Sica A, Balkwill F. Cancer related inflammation. Nature. 2008; 454: 436-444.

45. Hanahan D, Weinberg RA. Hallmarks of cancer: the next generation. Cell. 2011; 144: 646-674.

46. Pine JK, Morris E, Hutchins GG, West NP, Jayne DG, Quirke P, Prasad KR. Systemic neutrophil-to-lymphocyte ratio in colorectal cancer: the relationship to patient survival, tumour biology and local lymphocytic response to tumour. Br J Cancer. 2015; 113: 204-211.

47. Templeton AJ, McNamara MG, Seruga B, Vera-Badillo FE, Aneja P, Ocaña A, Leibowitz-Amit R, Sonpavde G, Knox JJ, Tran B, Tannock IF, Amir E. Prognostic role of neutrophil-to-lymphocyte ratio in solid tumors: a systematic review and meta-analysis. J Natl Cancer Inst. 2014; 106: dju124.

48. Shibutani M, Maeda K, Nagahara H, Ohtani H, Sakurai K, Yamazoe S, Kimura K, Toyokawa T, Amano R, Tanaka H, Muguruma K, Hirakawa K. Prognostic significance of the lymphocyte-to-monocyte ratio in patients with metastatic colorectal cancer. World J Gastroenterol. 2015; 21: 99669973.

49. Colotta F, Allavena P, Sica A, Garlanda C, Mantovani A. Cancer-related inflammation, the seventh hallmark of cancer: links to genetic instability. Carcinogenesis. 2009; 30: 1073-1081.

50. Ceze N, Thibault G, Goujon G, Viguier J, Watier H, Dorval E, Lecomte T. Pre-treatment lymphopenia as a prognostic biomarker in colorectal cancer patients receiving chemotherapy. Cancer Chemother Pharmacol. 2011; 68: 1305-1313.

51. Zhou X, Du Y, Huang Z, Xu J, Qiu T, Wang J, Wang T, Zhu W, Liu P. Prognostic value of PLR in various cancers: a meta-analysis. PLoS One. 2014; 9: e101119.

52. Templeton AJ, Ace O, McNamara MG, Al-Mubarak M, Vera-Badillo FE, Hermanns T, Seruga B, Ocaña A, Tannock IF, Amir. Prognostic role of platelet to lymphocyte ratio in solid tumors: a systematic review and meta-analysis. Cancer Epidemiol Biomarkers Prev. 2014; 23: 1204-1212.

53. Peng HX, Lin K, He BS, Pan YQ, Ying HQ, Hu XX, Xu T, Wang SK. Platelet-to-lymphocyte ratio could be a promising prognostic biomarker for survival of colorectal cancer: a systematic review and meta-analysis. FEBS Open Bio. 2016; 6: 742-750.

54. Tan D, Fu Y, Su Q, Wang H. Prognostic role of plateletlymphocyte ratio in colorectal cancer:A systematic review and meta-analysis. Medicine (Baltimore). 2016; 95: e3837.

55. Jain S, Harris J, Ware J. Platelets: linking hemostasis and cancer. Arterioscler Thromb Vasc Biol. 2010; 30: 23622367.

56. Labelle M, Begum S, Hynes RO. Direct signaling between platelets and cancer cells induces an epithelialmesenchymal-like transition and promotes metastasis. Cancer Cell. 2011; 20: 576-590. 
57. Schumacher D, Strilic B, Sivaraj KK, Wettschureck N, Offermanns S. Platelet-derived nucleotides promote tumorcell transendothelial migration and metastasis via $\mathrm{P} 2 \mathrm{Y} 2$ receptor. Cancer Cell. 2013; 24: 130-137.
58. Shankaran V, Ikeda H, Bruce AT, White JM, Swanson PE, Old LJ, Schreiber RD. IFNgamma and lymphocytes prevent primary tumour development and shape tumour immunogenicity. Nature. 2001; 410: 1107-1111. 